\title{
MERAMU KETENTUAN HUKUM ISLAM TERKAIT KHITAN PEREMPUAN
}

\author{
Oleh: Ashabul Fadhli * \\ Program Studi Sistem Informasi UPI-YPTK Padang \\ Jl. Raya Lubuk Begalung Padang \\ e-mail: fadhli_bull@yahoo.co.id
}

\begin{abstract}
Observing several academic documents that enrich the historical value, the discourse about circumcision apparently still presents interesting questions and ideas according to the conditions and social culture surrounding them. Cutting a small portion of the genitals on the implementation of circumcision is commonly done throughout the community on the child's age. The social values that legitimize female circumcision should be criticized because it may cause bad impact. Meanwhile, according to religious dogma, female circumcision is not a significant issue. Therefore, the practice of circumcision continues to be executed, but some of them lead to contradictory disagreement.
\end{abstract}

Kata kunci: khitan, perempuan, hukum Islam

\section{PENDAHULUAN} Kidentitas sosial dan wujud religiusitas masyarakat, kemudian dikritik pada rekontruksi pemahaman baru. Praktek khitan yang dipandang sunnah bagi laki-laki dan baik (kemuliaan) bagi perempuan, dikritisi sebagai dampak pergeseran nilai sosial yang ada, terutama bagi perempuan. Alasannya, legalitas serta risiko khitan bagi anak, khususnya anak perempuan, dapat memicu pengaruh psiko-sosial yang berdampak pada aspek fisiologis dan dikhawatirkan merugikan anak. Menurut paham ini, khitan perempuan menuai gejolak kegelisahan baru yang mengakar pada budaya patriarkhi pada masa terdahulu.

Sejak beredarnya surat edaran tentang larangan medikalisasi khitan perempuan bagi petugas kesehatan nomor: HK.00.07.1.3.1047a tanggal 20 April 2006; disebutkan bahwa khitan terhadap perempuan merupakan praktek perusakan alat kelamin perempuan, sehingga harus dilarang. Dilanjutkan dengan perumusan kesehatan RI No.1636/ MENKES/PER /XI/2010 serta Peraturan Pemerintah Republik Indonesia Nomor 61 Tahun 2014 tentang Kesehatan Reproduksi terkait ruang lingkup pelayanan kesehatan reproduksi menurut International Conference Population and Development

* Penulis adalah dosen pada UPI YPTK Padang 
(ICPD) tahun 1994 di Kairo (Penjelasan atas Peraturan Pemerintah Republik Indonesia Nomor 61 Tahun 2014 tentang Kesehatan Reproduksi, 2014).

Hal senada juga ditegaskan Majelis Ulama Indonesia (MUI) melalui fatwa MUI No. 9A tahun 2008 tentang hukum pelarangan khitan terhadap perempuan. Fatwa pelarangan khitan tersebut dilatarbelakangi oleh sejumlah pertimbangan yang utuh dan terintegrasi, diantaranya pertimbangan mengenai esensi atau dasar pensyariatan khitan pada perempuan, batas/tata cara serta pertimbangan lain di masa mendatang yang sehubungan dengan reproduksi perempuan. Karena itu, penjelasan dari dalil naqli yang juga didukung oleh Kementeri-an Pemberdayaan Perempuan, Kementerian Kesehatan RI serta Ikatan Bidan Indonesia (IBI) menguatkan bahwa khitan pada perempuan dapat menimbulkan risiko yang tidak sesuai dengan ketentuan syara'.

Kebijakan yang bersifat promotif, preventif, kuratif dan rehabilitatif ini secara esensial memberikan pemahaman terkait kesehatan reproduksi perempuan. Konkritnya, payung hukum di atas dimotori untuk menggagas upaya perlindungan kepada perempuan tentang pelaksanaan khitan yang harus dilakukan sesuai dengan ketentuan agama, standar pelayanan dan profesi untuk menjamin keamanan dan keselamatan (Husein Muhammad, 2001: 41). Sementara itu, bagi masyarakat yang membenarkan khitan perempuan, khitan sudah dianut dan menginternalisasi dalam sebuah tradisi turuntemurun yang sulit luntur, apalagi dihilangkan.
Merunut pada pembacaan penulis yang diselaraskan pada beberapa studi hadis, bahwasanya anjuran dalam melaksanakan khitan banyak disebutkan dalam beberapa hadis. Secara esensial, anjuran tersebut bersifat umum bagi laki-laki dan perempuan. Hanya saja, dalam beberapa hadis, terdapat batasanbatasan yang dibedakan pada praktek khitan perempuan, salah satunya dalam lafaz تنهكي yang berarti menghilangkan sebagian kecil. Artinya, pemahaman ini bukan bermakna sebaliknya, dengan menggunakan lafaz انتهك yang berarti menghilangkan dalam artian merusak atau menciderai. Sebab, perusakan atau pencideraan terhadap organ perempuan dapat memberikan pengaruh buruk (أحظى) bagi dirinya sebagai perempuan (baca: istri) dan laki-laki (baca: suami) yang dikemudian hari akan menjadi pasangan hidupnya.

Kendati demikian, ragam pendapat di kalangan ulama dan tokohtokoh Islam klasik maupun kontemporer, kian menjadikan tradisi ini tetap hidup dan meluas. Di antara pendapat tersebut adalah pendapat imam-imam mazhab seperti Imam Malik yang menyatakan bahwa khitan perempuan sebagai sesuatu yang disunnahkan, asalkan tidak berlebihan dalam hal menyayat atau memotong organ kelaminnya (Sunan alKubra, 2003: 561). Imam Ahmad ibn Hanbal menyatakan khitan bagi perempuan adalah wajib. Imam Abu Hanifah mengkategorikan khitan perempuan sebagai amalan baik dikarenakan bagian dari sunnah. Berbeda dengan pendapat Imam Syafi'i yang dianut mayoritas 
Muslim Indonesia, mewajibkan khitan bagi perempuan. Beberapa pendapat tersebut dikutip dari beberapa hadis yang menegaskan bahwa khitan disunnahkan bagi lakilaki dan kemuliaan bagi perempuan, hadis terkait lima hal yang menjadi fitrah bagi manusia, ataupun hadishadis lain terkait khitan dan cara pelaksanaannya yang akan penulis uraikan ke depan.

Untuk menjamin kepastian hukum terkait pensyariatan khitan bagi perempuan, tulisan ini akan diarahkan untuk melihat, Bagaimana bentuk anjuran berkhitan menurut ketentuan hadis nabawi? Berangkat dari keterangan tersebut, maka akan ditarik kesimpulan, Bagaimana tinjauan hukum Islam tentang khitan bagi perempuan? Untuk melacak hadishadis yang berhubungan dengan khitan perempuan tersebut, penulis menggunakan kitab Miftah Kunuz alSunnah dan didukung sebuah software hadis yang bernama al-Jami' al-Hadis melalui pendekatan tematis.

\section{KHITAN PEREMPUAN DALAM LITERASI HADIS}

Selain melakukan penelusuran hadis-hadis yang berbicara tentang khitan melalui kitab Miftah Kunuz alSunnah (Muhammad Fuad Abd alBaqi, 1978: 174), penulis juga berusaha melacaknya dengan menggunakan sebuah software hadis yang bernama Jami' al-Hadis. Di bawah ini akan dikutip beberapa hadis yang berkaitan dengan khitan perempuan. Dalam hal ini, penulis mencoba mengklasifikasikannya ke dalam dua tema utama, yaitu hadis yang berkaitan dengan tema khitan secara umum dan khitan perempuan secara khusus.

\section{Hadis-hadis yang Berbicara Menge- nai Khitan Secara Umum}

Dalam beberapa hadis yang menggunakan lafaz ختان didapati bunyi hadis sebagai berikut:

Hadis-Hadis yang Berbicara Tentang Wajibnya Mandi ketika Bertemunya Dua Khitan:

$$
\text { ورساذ التقى الختانان فقد وجب الغسل ، فعلته أنا }
$$

Apabila bertemu dua khitan, maka diwajibkan baginya untuk mandi. Aku dan Rasulullah pernah melakukannya hingga kamipun mandi (HR. Ibn Majah)

Hadis di atas (Sunan Ibn Majah, Hadis No. 608, t.th: 118) berbicara tentang ketentuan wajibnya mandi ketika bertemunya dua khitan. Pembicaraan hadis di atas mengarah pada satu term yaitu tentang kewajiban mandi ketika bertemunya dua khitan (laki-laki dan perempuan). Kewajiban ini diberlakukan bagi laki-laki dan perempuan sebagai suami dan istri ketika melakukan hubungan kelamin. Meskipun begitu, maksud dan tujuan hadis-hadis di atas adalah sama dan semuanya berstatus shahih. 
Hadis-Hadis Tentang PerkaraPerkara yang Dianggap Fithrah

$$
\text { والفطرة خمس ، أو خمس من الفطرة : الخنان ، ولمداد ، ونتف الإبط ، وتقليم الأظفار }
$$

Terdapat lima perkara fitrah yaitu khitan, istihdad, memotong kuku, mencabut bulu ketiak dan mencukur kumis (HR. Bukhari)

Hadis di atas (Shahih alBukhari, Hadis No. 5889, 2002: 160) memiliki pemaknaan yang lebih mengerucut dibanding hadis sebelumnya, terkait 5 (lima) perkara yang dianggap fithrah yaitu berkhitan, mencukur rambut kemaluan, mencabut bulu ketiak, memotong kuku, dan memotong kumis. Dari segi keshahihannya kedua hadis di atas berstatus sahih karena diriwayatkan oleh Imam Bukhari dan Imam Muslim di dalam kedua kitab sahih mereka.

\section{Hadis yang Berbicara Mengenai Khitan Secara Khusus}

\section{Khitan Itu Sunnah bagi Laki-Laki dan Kemulian bagi Perempuan}

$$
\text { الختان سنة للرجال ، مكرمة للنساء }
$$

Khitan disunnahkan bagi laki-laki dan dimuliakan bagi perempuan (HR. Ahmad).

Hadits ini (Musnad Imam Ahmad ibn Hambal, Musnad al-Imam Ahmad ibn Hanbal, Hadis No. 20719, 2001: 319) dijumpai bahwa hadis yang berbicara tentang kemuliaan bagi perempuan untuk melakukan khitan tidak yang diriwayatkan oleh Bukhari, Muslim bahkan oleh Ashab al-Sunan. Dalam jajaran Kutub Tis'ah, hanya diriwa- yatkan oleh Imam Ahmad saja, itu pun hanya berjumlah satu hadis saja. Sedangkan kebanyakan ulamaulama yang meriwayatkan hadishadis ini menganggap statusnya lemah. Begitu juga dengan Yusuf alQardhawi ketika mengomentari hadis ini mengatakan bahwa hadis ini berstatus dhai'f.

Hadis-Hadis tentang Tata Cara Khitan

$$
\text { وأذا ختنت فلا تنهكي ، فإن ذلك أحظى للمرأة , }
$$

Apabila dikhitan jangan berlebihan, sebab yang demikian itu kebahagian bagi perempuan dan kesenangan bagi perempuan (HR. Al Baihaqi)

Melalui keterangan hadis di atas, (Sunan al-Kubra, Hadis No. 17559, 2003: 561) dan keterangan hadis berikut:

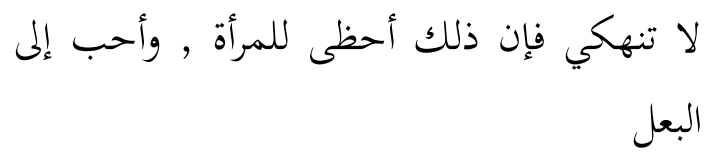

Jangan berlebihan (dalam mengkhitannya), sebab yang demikian itu paling membahagiakan perempuan dan paling disukai laki-laki/suaminya (HR. Abu Daud)

(Sunan Abu Daud, Hadis No. 5271, t.th: 368), penulis mencoba mengetengahkannya bahwa dalam tata cara pelaksanaan khitan perempuan terdapat poin penting yang harus dipahami sebelum diselenggarakannya khitan. Bagi organ perempuan yang dikhitan sedapat mungkin dilakukan pemotongan yang kadarnya sedikit. Pemaknaan ini diambil dari lafaz تنهكي yang berarti menghilangkan sebagian kecil dan bukan sebaliknya dengan menggunakan 
lafaz انتهك yang berarti menghilangkan dalam artian merusak atau menciderai. Sebab, perusakan atau pencideraan terhadap organ perempuan dapat memberikan pengaruh buruk (أحظى) bagi dirinya sebagai perempuan (baca: istri) dan laki-laki (baca: suami) yang di kemudian hari akan menjadi pasangan hidupnya.

Sedangkan khitan bagi lakilaki, lafaz سنة للرجال sekiranya dapat dijadikan tolak ukur tentang anjuran berkhitan bagi laki-laki. Belum didapati hadis yang menegaskan cara berkhitan laki-laki sebagaimana perempuan kecuali faktor kesunnahannya. Disunnahkannya khitan bagi laki-laki ini menjadi dorongan yang bersifat persuasif. Hal ini disebabkan bahwa Rasulullah SAW pun melakuوأحب إلى kan khitan. Hanya saja, lafaz secara implisit menurut penulis mengarah pada kehati-hatian pada pelaksanaan khitan pada perempuan. Indikasinya, ketika khitan pada perempuan tidak dijalankan sesuai anjuran hadis-hadis di atas, dikhawatirkan akan mengganggu kegiatan seksual - pasangan suamiistri serta keharmonisan rumah tangga, yang dalam konteks ini adalah kesenangan suami.

Berangkat dari keterangan di atas, asumsi awal yang dapat diberikan adalah bahwasanya hadishadis tersebut diketahui diriwayatkan dari jalan yang berbeda-beda yang terhukum dha'if. Dalam pertikaian ini, Syaikh al-Bani justru menshahihkan riwayat tersebut dikarenakan banyaknya riwayat yang menyampaikan dengan bahasa dan makna yang senada. Sebaliknya, Yusuf al-Qardhawi memaparkan komentar Abu Dawud tentang salah seorang rawinya yang bernama Muhammad ibn Hasan bahwa dia tidak dikenal (majhul), dan hadis ini dha'if. Akan tetapi al-Hafizh 'Abd alGhani ibn Sa'id menyebutkan bahwasanya dia tidak majhul, dia adalah Muhammad ibn Sa'id ibn Hasan, yang dibunuh oleh alManshur karena kezindikannya. Mereka mengatakan bahwa dia telah memalsukan 4000 hadis untuk menyesatkan kaum Muslimin.

\section{MEMPERTEGAS SUBSTANSI KHITAN PEREMPUAN}

Ditemui dalam lembaran Kamus al-Munjid, khitan secara bahasa berasal dari kata ختان yang merupakan mashdar dari kata kerja - ختن يخن yang berarti memotong atau potongan sesuatu (Luis Ma'luf, 1908: 169). Sedangkan menurut istilah, khitan dimaknai sebagai bagian yang dipotong dari kulit penis laki-laki dan bagian dari vagina/ klitoris perempuan (Ibn Mandhûr al-Afriqî, 1994: 138). Dengan lebih terperinci, Ibn Hajar al-Asqalani di dalam kitabnya Fath al-Bari mengungkapkan bahwa khitan pada laki-laki adalah memotong kulit yang menutupi kepala kafsyah (kepala penis), sedangkan bagi perempuan dilakukan dengan cara memotong bagian atas vagina (klitoris), yang terletak di atas 
lobang senggama, yang berbentuk seperti kurma atau jengger ayam (Ibn Hajar al-Asqolanî, 1993: 530).

Dalam bukunya al figh al Islami wa adillatuhu karya Wahbah alZuhaili menjelaskan, khitan perempuan dimaknai sebagai upaya memotong sedikit mungkin dari kulit pada bagian farji atau klistoris. Zuhaili menganjurkan agar pemotongan tersebut tidak dilakukan secara berlebihan. Anjuran ini bertujuan agar perempuan dapat mencapai kesempurnaan kenikmatan pada saat bersenggama (Wahbah alZuhaili, 1989: 356).

Sementara itu, Sayyid Sabiq dengan lebih tegas mengatakan bahwa khitan bagi laki-laki berupa pemotongan kulit yang menutupi kafsyah agar tidak menyimpan kotoran, mudah dibersihkan ketika kencing, dan menambah kenikmatan ketika bersenggama. Sedangkan untuk perempuan adalah dengan memotong bagian atas dari vaginanya (klitoris). Khitan ini merupakan sunnah qadimah (Sayyid Sabiq, 1987: 36).

Sedangkan dalam kacamata medis, menurut beberapa tokoh, tidak ditemukan teori mendasar mengenai ilmu kesehatan yang melegitimasi tindakan khitan pada perempuan. Khitan dalam dunia medis hanya ditegaskan pada lakilaki yang terbukti memiliki nilai positif. Apalagi, tindakan khitan bagi laki-laki didukung kuat oleh nilainilai agama (Graham Masterton, 2003: 275).

Di sisi lain, WHO (World Health Organization) mendefenisikan khitan perempuan ini dengan defenisi yang berbeda. Menurut putusan resmi WHO, khitan perempuan merupakan semua tindakan atau prosedur yang meliputi pengang-katan sebagian atau seluruh dari organ genital eksternal perempuan (klitoris, labia minora, labia mayora, dan vulva) atau bentuk perlukaan lain terhadap organ genital perempuan dengan alasan budaya, mitos, agama atau alasan medis lainnya (Sharon J. Reeder dkk, 2011: 320-327).

Dalam hal ini, khitan perempuan lebih familiar dengan sebutan Female Genital Mutilation (FGM). FGM mencakup seluruh prosedur pemotongan sebagian atau seluruh genitalia eksternal atau bentuk pelukaan lain pada genitalia perempuan. Kendati demikian, khitan perempuan dilakukan berbeda-beda, dapat hanya sebatas membasuh ujung klitoris, menusuk ujung klitoris dengan jarum, membuang sebagian klitoris, membuang seluruh klitoris dan membuang labia minora (bibir kecil vagina) serta seluruh klitoris. Bahkan, temuan lain menunjukkan bahwa hampir seluruh labia mayora (bibir luar vagina) dijahit, terkecuali pada ujung kecil labia mayora yang dibiarkan merenggang atau terbuka. Bagian ini dibiarkan terbuka sebagai sebagai jalan dalam proses menstruasi (Elga Serapung, dkk, 1999: 118).

Peluang untuk dilakukannya khitan terhadap perempuanpun begitu kental dengan nilai sejarah. Ahli etnografis, Wilken (1847-1891) menyebutkan, bahwa praktek khitan telah dipelopori oleh oleh bangsabangsa pengembara seperti bangsa Semit, Hamit dan Hamitoid di Asia Barat Daya dan Afrika Timur. Begitu juga dengan bangsa Negro yang berdomisili di Asia Timur dan Afrika Selatan (Haifa A. Jawad, 2002: 196). Praktek ini juga diperkirakan ber- 
kembang Sudan, Mesir, Ethiopia hingga daerah-daerah di tepi laut merah (Hasan Hathout, 1996: 53-57). Kemudian berkembang ke wilayah Asia Tenggara seperti Malaysia dan Indonesia. Percampuran nilai budaya dan nilai agama rupanya semakin menguatkan masyarakat untuk mentradisikan khitan perempuan.

Dari berbagai argumen di atas, terlihat perbedaan pandangan dalam memaknai khitan dan khitan perempuan antara ulama Islam dan WHO. Perbedaan mendasar dari kedua kelompok ini adalah dari metode khitan perempuan itu sendiri. Ulama dengan merujuk kepada hadis-hadis yang ada memahami bahwa khitan perempuan dilakukan dengan memotong sedikit bagian kecil atas vagina yang lebih dikenal dengan klitoris. Sedangkan WHO melihatnya sebagai setiap tindakan pengangkatan sebagian atau seluruh organ genital eksternal perempuan.

Secara historis, praktek khitan perempuan ini diduga telah dimulai sejak 4000 tahun silam, sebelum kemunculan agama yang terorganisasi. Praktek tersebut juga ditemukan pada Mummi Mesir yang berstatus kaya raya dan berkuasa. Ahli Antropologi menduga, dipraktekkannya khitan pada jaman Mesir Kuno adalah sebagai bentuk pencegahan masuknya roh-roh jahat melalui vagina. Tradisi khitan perempuan sudah menjadi ritual dalam proses perkawinan. Praktek khitan pharaonic sebagai ritual sebelum pernikahan ditemukan sejak tahun 1350 SM (Jurnal Perempuan, 2002:
25). Begitu juga pada zaman Romawi, budak-budak perempuan diwajibkan melakukan khitan. Pada masa itu, budak perempuan yang dikhitan harganya jauh lebih tinggi dari budak perempuan yang tidak dikhitan. Karena, budak yang dikhitan dinilai sebagai perempuan yang masih suci atau perawan, dipercaya belum disentuh oleh lakilaki lain maupun oleh majikannya.

Tradisi khitan juga ditemui dalam tradisi agama samawi yang secara historis memiliki akar yang kuat pada ajaran Nabi Ibrahim sebagai manusia pertama yang diperintahkan untuk menjalankan khitan. Dalam Islam, tradisi ini dikenal sebagai millah Ibrahim As. yang dikuatkan dalam (Q.S. al-Hajj (22): 78):

$$
\begin{aligned}
& \text {...وما جعل عليكم في الدين من حرج ملة ابيكم : } \\
& \text { ابراهم.... }
\end{aligned}
$$

... Dan Dia sekali-kali tidak menjadikan untuk kamu dalam agama suatu kesempitan. (Ikutilah) agama orang tuamu Ibrahim...(Q.S. al-Hajj [22]: 78)

Ayat di atas dikuatkan oleh hadis Shahih Bukhari sebagai berikut:

$$
\begin{aligned}
& \text { اختتن ابراهيم خليل الرحمان بعد ما اتت عليه } \\
& \text { تثانون سنة واختتن بالقدوم }
\end{aligned}
$$

Nabi Ibrahim AS berkhitan setelah memasuki usia delapan puluh tahun dan beliau berkhitan dengan qudum (HR. Bukhari)

Meskipun dalam tradisi Ibrahim As. secara eksplisit dijelas- 
kan pembenaran melakukan khitan, namun tetap saja khitan pada perempuan masih diperselisihkan. Peselisihan ini mengisyaratkan kemungkinan adanya intervensi tradisi dan budaya (social culture) masyarakat Arab sebelum Islam datang. Kemudian cara pikir ini dianggap stimulan yang mempengaruhi kebijakan pengambilan ijtihad ulama dalam memahami teks-teks alQur'an dan hadis Nabi SAW (Husein Muhammad, 2001: 43).

Mengutip pendapat Nawal el Sadawi yang mempertanyakan bahwa terdapat perbedaan pada fungsi dan tujuan khitan bagi lakilaki dan khitan pada perempuan. Bagi laki-laki, khitan akan memberikan pengaruh pada kenikmatan melakukan hubungan dalam segi durasi dan kepuasan secara seksual. Sebaliknya bagi perempuan, tidak akan memberikan pengaruh berarti secara seksual. Bagi Nawal, khitan pada perempuan hanya mempertegas adanya per-bedaan gender terkait keunggulan laki-laki dan merugikan perempuan. Dengan kata lain, khitan perempuan diasumsikan sebagai sebuah mekanisme pengebirian nafsu seksual melalui pemotongan sebagian atau seluruh organ vital perempuan. Khitan dalam konteks ini dipertegas melalui keinginan laki-laki untuk mengendalikan seksualitas perempuan. Padahal, dalam studi lebih lanjut ditemukan, khitan pada perempuan banyak memberikan efek negatif berupa infeksi ringan hingga komplikasi kronis (Munawwar Ahmed Annes, 1992: 66).

Praktek medis yang merugikan perempuan ini kemudian dipresentasikan sebagai penyerangan seksual yang dimotivasi oleh suatu keinginan untuk menyakiti, mendominasi atau menghukum perempuan secara fisik. Ketidak-tahuan dan ketidak berdayaan perempuan untuk memberikan cara pandang yang moderat dan terukur memicu praktek khitan senantiasa dilanggengkan (Sharon J. Reeder dkk, 2011: 320). Penganiayaan seksual tertuju pada organ seks eksternal perempuan yang disebut vagina dan vulva. Vagina merupakan struktur internal spesifik, sementara vulva hanyalah alat kelamin eksterior yaitu bukaan vagina yang terlihat dari luar tubuh saja. Adapun bagian vulva antara lain (1) labia mayora atau bibir besar atau bantalan jaringan ikat longgar berlemak yang terbentuk dari otot polos. Bagian ini berisi kelenjer-kalenjer keringat dan minyak yang disebut sebagai aroma seksual; (2) labia minora atau bibir kecil dalam vulva yang berfungsi melindungi bukaan vagina (introitus) dan bukaan urethra (meatus) dengan ukuran yang bervariasi; (3) mons pubis atau gundukan lemak empuk yang terdapat tepat di atas tulang panggul bagian depan; (4) Kalenjer Bartholin atau kalenjer yang berlokasi di dekat bukaan vagina dan berfungsi sebagai alat memproduksi cairan/lender sekresi; dan (5) Klitoris atau tonjolan kecil sensitif pada organ seks perempuan.

Klitoris adalah organ yang tidak terlihat dari luar dan sangat sensitive terhadap ransangan. Saat terjadi ransangan seksual klitoris mampu berereksi, membesar dan tudungnya tertarik sehingga kepala klitoris lebih terbuka. Klitoris memiliki peran penting dalam rangsangan dan orgasme (Sri Noor Verawaty dan Liswidyawati Rahayu, 
2012: 32-35). Klitoris ditutupi oleh lipatan kulit berupa tudung klitoris yang mirip dengan kulup pada ujung penis laki-laki. Namun tidak seperti penis, klitoris tidak memiliki urethra. Jaringan pelindung ini adalah bagian dari labia minora. Bagian kepala klitoris memiliki ujung saraf yang sangat banyak, bahkan lebih banyak dari jumlah saraf yang terdapat pada kepala penis laki-laki (Sri Noor Verawaty dan Liswidyawati Rahayu, 2012: 35-36).

Sehubungan dengan keterangan di atas, klitoris merupakan organ seks eksternal perempuan yang mengalami pemotongan (genital) pada ujung klitoris. Akibatnya, organ eksternal tersebut tidak lagi menjadi sempurna. Sebab klitoris terbentuk dari kesatuan jaringan spons yang ujungnya terlihat dari luar sementara bagian dalamnya memanjang dan bercabang dua seperti garpu (crura) ke bawah di tepi bukaan vagina hingga ke perineum. Jadi, fungsi klitoris yang begitu penting dalam proses orgasme perempuan hilang terpotong seiring dilakukannya khitan.

Menurut paham ini, khitan perempuan tidak sejalan dengan kebijakan International Conference Population and Development (ICPD) tahun 1994 di Kairo tentang kesehatan reproduksi seperti sunat perempuan yang mengarah pada kekerasan seksual.

International Conference for Population and Development (ICDP) merupakan sebuah konferensi internasional yang membahas aksi untuk populasi dan pembangunan di Kairo. Lebih dari 179 negara pada tahun 1994 hadir dalam konferensi ini. Program aksi yang dicanangkan adalah kesehatan reproduksi, kesehatan dan hak reproduksi dan seksual. Ini kemudian mengubah arah paradigma pembangunan yang mempromosikan Sexual and Reproductive Health and Rights (SRHR). SRHR kemudian menjadi jantung dari pembangunan demografi. Sedikit dari agendanya mencakup kesetaraan gender dan hak asasi manusia, salah satunya berkenaan mengenai khitan perempuan.

Intrumen international tersebut rupanya berperan besar dalam suksesi agenda politik perempuan di Indonesia secara nasional. Baru pada tahun 2007 dan 2012 Komite Convention on Elimination off All Form Descrimination Against Women (CEDAW) merekomendasikan agar pemerintah Indonesia mengembangkan rencana aksi untuk menghapus segala bentuk kekerasan berbasis gender. Aspek-aspek yang selama ini menjadi kendala pencapaian kesetaraan gender adalah adanya bentukbentuk deskriminasi terhadap perempuan, yang memberikan perlakuan berbeda sekaligus merugikan perempuan dalam keadaan tertentu (Siti Ruhaini Dzuhayatin, 2007: 6-7).

Berangkat dari hal di atas, CEDAW turut merekomendasikan kampanye publik untuk mengubah persepsi budaya tentang khitan perempuan, dan memberikan pendidikan publik bahwa praktik khitan 
perempuan adalah pelanggaran HAM perempuan dan anak.

Begitu juga dengan tujuan diselenggarakannya pelayanan kesehatan reproduksi bagi remaja perempuan (Peraturan Pemerintah Republik Indonesia Nomor 61 Tahun 2014 tentang Kesehatan Reproduksi Pasal 11 ayat 1). Dalam Peraturan Pemerintah Republik Indonesia Nomor 61 Tahun 2014 tentang Kesehatan reproduksi dijelaskan bahwa pelayanan kesehatan sistem reproduksi adalah pelayanan kesehatan yang ditujukan kepada suatu rangkaian organ, interaksi organ, dan zat dalam tubuh manusia yang dipergunakan untuk berkembang biak. Selain itu pemberian pelayanan kesehatan reproduksi remaja harus disesuaikan dengan masalah dan tahapan tumbuh kembang remaja serta memperhatikan keadilan dan kesetaraan gender, mempertimbangkan moral, nilai agama, perkembangan mental, dan berdasarkan ketentuan peraturan perundang-undangan (Peraturan Pemerintah Republik Indonesia Nomor 61 Tahun 2014 tentang Kesehatan Reproduksi Pasal 11 ayat 2 dan 3). Huzaemah T Yanggo, Guru Besar Fakultas Syariah dan Hukum UIN Syarif Hidayatullah Jakarta, mengungkapkan berbeda bahwa perempuan muslim yang tidak dikhitan, dinilai melanggar hak asasi manusia (HAM). Karena itu, anak perempuan harus dikhitan orang tuanya, karena manfaat bagi yang bersangkutan sangat besar (Huzaemah T Yanggo, Media Indonesia, 2 Februari 2013)

Jika merujuk pada kebijakan yang dikeluarkan negara-negara Islam tentang signifikansi menerapkan khitan, tidak ditemui kata mufakat dalam persoalan pengambilan hukum (istinbathul ahkam). Sebagian mereka melaksanakan khitan dengan pertimbangan bahwa khitan baik diterapkan bagi anak perempuan. Namun jika sekiranya khitan dapat menimbulkan persoalan lain di masa mendatang, maka dianjurkan untuk meninggalkan. Dalam kaidah fikih disebut:

$$
\text { الضرار يزال }
$$

Kaidah ini merupakan salah satu dasar fondasi di dalam prinsip ajaran Islam yang dapat diterapkan dalam seluruh permasalahan fikih. Kaidah ini memberikan pengertian bahwa sesuatu yang bersifat dharar maka harus dihilangkan. Keringanan hukum ini terjadi karena adanya kondisi darurat atau kondisi normal yang menyulitkan (mafsadat) apabila tetap dilaksanakan (Ibnu al-Laham, 1956: 120). Jauh berbeda dengan lakilaki, khitan bagi laki-laki sudah menjadi bagian dari syiar Islam oleh para ulama-ulama terdahulu. Di balik anjurannya sebagai sunnah, untuk mengukuhkannya, khitan bagi laki-laki dapat dipaksakan bagi mereka yang menolak. Paksaan ini beralasan pada keistimewaan yang diperoleh umat Islam dalam melaksanakan khitan (Ibnu al-Laham, 1956: 443).

Dharar yang disebutkan di atas dimaksudkan bahwa stereotype dalam lafaz مكرمة للنساء bukanlah makna tunggal dan satu-satunya alasan yang menjadikan perempuan mulia karena melakukan khitan. Dengan tegas Qardhawi menyampaikan bahwa pencapaian kemuliaan yang sesungguhnya dapat diraih laki-laki maupun perempuan melalui instru- 
men amaliyah yang bersifat 'ubudiah dan muamalah. (Yusuf al-Qardhawi, 2009: 443).

\section{PANDANGAN ULAMA TERHA- DAP HUKUM KHITAN PEREM- PUAN}

Menindaklanjuti dari keterangan hadis-hadis yang telah diuraikan sebelumnya, secara umum para ulama sepakat mengatakan bahwa khitan itu suatu hal yang masyru' atau disyari'atkan. Pensyariatan ini berlaku bagi laki-laki maupun perempuan, sebagaimana yang penulis kutip dari Ibn Hazam dalam bukunya Maratibul Ijma' dan Ibn Taimiyah dalam bukunya Majmu' alFatawa. Namun mereka berbeda pendapat dalam menetapkan hukumnya, apakah khitan itu wajib atau tidak.

Pendapat para ulama terkait hukum khitan bagi perempuan muslimah sebagai berikut:

\section{Golongan yang Mewajibkan}

Pendapat ini dianut oleh para ulama bermazhab Syafi'i, Hambali, dan Syahnun, salah seeorang ulama dari mazhab Maliki (Muhammad Khalid Manshur, t.th: 174). Menurut mereka, khitan adalah salah satu kalimat yang diperintahkan Allah sebagai ujian terhadap Nabi Ibrahim sebagaimana yang diriwayatkan oleh Ibn Abbas. Dan biasanya seseorang itu diuji Allah dengan sesuatu yang wajib (Muhammad Khalid Manshur, t.th: 176). Dalildalil yang mereka gunakan untuk memperkuat argumentasi mereka diantaranya

a. Firman Allah di dalam Q.S alBaqarah (2): 124 yang artinya:

"Dan ingatlah ketika Ibrahim diuji Tuhannya dengan beberapa kalimat perintah dan larangan, lalu Ibrahim melaksanakannya"

b. Firman Allah di dalam Q.S alNahl (16): 123 yang artinya:

"Kemudian Kami wahyukan kepadamu agar engkau mengikuti agama (ajaran) Ibrahim dengan lurus".

Ayat di atas berisi perintah untuk mengikuti ajaran Ibrahim As., dan khitan merupakan salah satu ajarannya. Maka khitan termasuk ajaran Ibrahim yang wajib diikuti, karena pada dasarnya sebuah perintah itu berhukum wajib selagi tidak ada dalil yang memalingkannya kepada hukum lainnya (Muhammad Khalid Manshur, t.th: 176).

Akan tetapi sebagian ulama membantah pendalilan dengan dua ayat ini, karena walaupun Ibrahim mengerjakannya, belum tentu ia adalah sesuatu yang diwajibkan kepadanya, boleh jadi dia hanya sekedar sesuatu yang dianjurkan saja untuk dikerjakan (Muhammad Khalid Manshur, t.th: 176).

c. Hadis yang diriwiyatkan dari Aisyah R.A

Dalam hadis tersebut Aisyah R.A berkata: Jika dua khitan bertemu, maka wajiblah mandi. Aku dan Nabi SAW pernah mengerjakannya, maka kamipun 
mandi. (H.R Ahmad, Ibn Majah, al-Syafi'i, Ibn Hibban, Hibban, dan al-Thabrani)

Hadis ini mengindikasikan bahwa bahwa perempuan Arab saat itu juga berkhitan. Ini perkara yang cendrung diperselisihkan. Bisa jadi khitan pada saat itu hanya sekedar kebiasan yang biasa mereka lakukan. Perselisihan kerap muncul ketika dipertanyakan apakah khitan bagi perempuan wajib atau sunnah (Muhammad Khalid Manshur, t.th: 176).

d. Sabda Rasulullah SAW kepada seseorang yang masuk Islam;

Dari 'Utsaim ibn Kulaib dari bapaknya dari kakeknya bahwasannya dia datang kepada Rasulullah, seraya berkata: "Saya telah masuk Islam." Maka Rasulullah bersabda, "Buanglah darimu rambut kekufuran dan berkhitanlah." (H.R Abu Dawud).

e. Hadis yang diriwayatkan oleh Zuhri. Bahwa Rasulullah SAW bersabda: "Barangsiapa yang masuk Islam, maka hendaklah berkhitan, sekalipun dia telah besar". Hadis ini termasuk dalam marasil nya al-Zuhri, dan dia termasuk hadis mursal yang paling lemah yang tidak boleh berhujjah dengannya (Muhammad Khalid Manshur, t.th: 178).

f. Hadis dari Ummu 'Athiyyah alAnshariyyah

Bahwasanya seorang perempuan di Madinah mengkhitan (seorang perempuan), maka Nabi SAW. bersabda kepadanya: "Janganlah berlebihan (memotongnya), karena ia adalah bagian kenikmatan bagi perempuan, dan menambah kecintaan suami." (H.R. Abu Dawud).

\section{Golongan yang Menganggap Sunnah}

Mereka yang menganggapnya sunnah dari pengikut mazhab Hanafi, Maliki, salah satu pendapat dari Imam Ahmad, satu pendapat yang Syadz dari mazhab Syafi'i, dan Zahiri (Muhammad Khalid Manshur, t.th: 175) Adapun dalildalil yang mereka pakai untuk melandasi pendapat mereka diantaranya adalah:

a. Hadis yang diriwayatkan oleh Abu Hurairah

Rasulullah SAW bersabda; Ada lima hal yang merupakan fitrah: Khitan, membuang bulu kemaluan, memendekkan kumis, memotong kuku, dan mencabut bulu ketiak.

Adapun yang dimaksud fitrah di sini adalah sunat, artinya khitan itu hukumnya sunat bukan wajib, oleh karena itu dalam hadis ini Rasulullah SAW menyebutnya bersamaan dengan hal-hal yang disunatkan. Dan hadis ini bersifat umum, tanpa membedakan antara laki-laki dan perempuan (Muhammad Khalid Manshur, t.th: 5).

b. Diriwayatkan bahwa Rasulullah SAW bersabda khitan itu adalah sunnah bagi kaum laki-laki dan kehormatan bagi kaum perempuan".

Zahir Hadis ini menunjukkan bahwa khitan itu tidak wajib, baik bagi laki-laki maupun perempuan. (Muham-mad Khalid Manshur, t.th: 181). Akan tetapi Yusuf al-Qardhawi ketika mengo- 
mentari hadis ini mengatakan bahwa hadis ini berstatus dhai'f (Yusuf al-Qardhawi, 2009: 514). Sedangkan yang dimaksud dengan "kehormatan bagi perempuan" bahwa ia adalah sesuatu yang dianggap baik untuk mereka, dan tidak ada satu nas agamapun yang menyatakan wajib atau istihbabnya (Yusuf alQardhawi, 2009: 514).

\section{Golongan yang Menganggap Khi-} tan Sekedar Anjuran Saja atau Mubah.

Sedangkan mereka yang berpendapat bahwa khitan itu diwajibkan bagi laki-laki, dan hanya merupakan kehormatan bagi perempuan, berdalil dengan dalil-dalil kelompok pertama, dan mengatakan bahwa khitan bagi laki-laki lebih kuat, karena khitan bagi laki-laki tujuannya membersihkan sisa air kencing dan najis yang terdapat pada kulit tutup kepala zakar, sedangkan suci dari najis merupakan syarat sah shalat. Sedangkan khitan bagi perempuan hanyalah untuk mengecilkan dan menstabilkan syahwatnya, yang ini hanyalah untuk mencari sebuah kesempurnaan dan bukan sebuah kewajiban (Abdul Munir, t.th: 5).

Yusuf al-Qardhawi di dalam Fatawa Mu'ashirah berpandangan bahwa tidak ada satupun dalil shahih dan sharih yang mewajibkan atau menganggap sunnah khitan bagi perempuan, baik dari al-Qur'an, Sunnah, ijma', maupun qiyas. Qardhawi juga mengungkapkan bahwa para ulama sepakat akan kebolehannya. Jadi tidak ada satupun ulama yang mengatakan bahwa khitan adalah sesuatu yang diharamkan atau dimakruhkan dengan makruh li tanzih atau li tahrim. Oleh karenanya, tidak dipandang baik seseorang yang mencela orang yang melakukannya atau menganggapnya telah melakukan perbuatan melawan hukum, kecuali jika dilakukan secara berlebihan hingga salah satu pihak merasa dirugikan. (Abdul Munir, t.th: 516).

\section{PENUTUP}

Melalui uraian di atas dapat ditarik kesimpulan bahwa:

1. Dari beberapa hadis yang mewajibkan khitan terutama bagi perempuan, kebanyakan didasarkan pada tuntutan untuk mengikuti ajaran Ibrahim As., dan keterangan lain yang disebutkan sebagai sunnah serta peluang meraih kemuliaan. Anggapan ini cenderung disebabkan pada keadaan pelaksanaan khitan pada saat itu yang lebih mengarah pada faktor perilaku, yaitu kebiasaan yang menggejala dan kemudian berkembang sebagai nilai-nilai di tengah masyarakat.

2. Keterangan dari hadis-hadis tentang pensyariatan khitan yang sangat bersifat umum, mengindikasikan bahwa khitan bagi perempuan dipahami hanya sebagai sebuah anjuran dan bukan kewajiban. Keadaan ini disebabkan, sulit sekiranya ditemukan alasan 
mendasar terkait tujuan diberlakukannya khitan perempuan sesuai tuntutan syariat yaitu pada aspek kemaslahatan (maslahat) menimbang resiko kerusakan (mafsadat) di kemudian hari. Singkatnya, penerapan khitan berpeluang untuk menciderai aktivi-

\section{DAFTAR PUSTAKA}

Abdul Munir, Akmal, Hukum dan Hikmah khitan Perempuan Menurut Hukum Islam

Abdul Qadir, Atha, Muhammad, Sunan al-Kubra, Beirut: Daa alKutub, 2003

Abu Abdullah Muhammad ibn Yazid, Ibn Majah t.th. Sunan Ibn Majah, Beirut: Daar Ihya alKitab al-'Arabiyah.

Al-Afriqî,Ibn Mandhûr. 1994. Lisân al-'Arab, juz 13, Beirut: Dar Shadir

Ahmad ibn Muhammad ibn Hanbal, Abu Abdullah. 2001. Musnad alImam Ahmad ibn Hanbal, Beirut: Muassasah al-Risalah.

Amin, Ma'ruf. 2010. Himpunan Fatwa Majelis Ulama Indonesia, Jakarta: Majelis Ulama Indonesia.

Anas,Malik ibn. 1985. al-Muwattha', Beirut: Dar Ihya' al-Turats al'Arabiy.

al-Asqolanî, Ibn Hajar. 1993. Fath alBarî fi Syarh Sahîh al-Bukharî, juz 11, Beirut: Dar al- Fikr.

Dzuhayatin, Siti Ruhaini. 2007. Gender Dalam Tatanan Internasional dan Nasional, dalam Agama, Politik Global dan tas perempuan secara fisik maupun psikologis. Meskipun begitu, keumuman dari makna seruan khitan perempuan tersebut tentu tidak serta menyebabkan khitan perempuan terhukum dilarang (bathil).

Hak-Hak Perempuan, Jakarta: PPIM.

Fuad Abd al-Baqi, 1978. Muhammad, Miftah Kunuz alSunnah, Lahore: Ma'arif.

Hathout, Hasan, 1996. Revolusi Seksual Perempuan, Obstetri dan Ginekologi dalam tinjauan Islam, Bandung: Mizan.

Husain, Ahmad Ibn. 2003. As-Sunan al-Kubra, Beirut: Daar al-Kutub al-'Alamiyyah.

Ibnu Ismail Abu Abdullah Al bukhari Al Ja'fi, Muhammad. 1422 H. Al Jami'u al-Musnad ashShahih, juz 9, Beirut: Daar Thauq al-Najah.

Jawad, A. Haifa. 2002. Otentitas Hakhak Perempuan Perspektif Islam dan Kesetaraan Gender, Yogyakarta: Fajar Pustaka Baru.

Jurnal Perempuan. 2002. Hentikan Kekerasan Terhadap Perempuan, Jakarta: Yayasan Jurnal Perempuan.

Khalid Manshur, Muhammad. t.th. al-Ahkam al-Thibbiyyah alMuta'alliqah bi al-Nisa' fi alFigh al-Islami, cet. 2, Yordania: Dar al-Nafa' is. 
Majah, Ibn. t.th. Sunan Ibn Majah, cet. 1, Riyad: Maktabah al-Ma'arif.

Masterton, Graham. 2003. Menikmati Kepuasan Sejati, Jakarta: PT Kentindo Publisher.

Ma'luf, Luis. 1908. Kamus al-Munjîd, Beirut: al-Maktabah alKatolikiyah.

Muhammad, Husein. 2001. Fiqh Perempuan: Refleksi Kiai Atas Wacana Agama Dan gender, Yogyakarta: LKiS.

Al-Nasa'I. 2001. Kitab Sunan al-Kubra, Beirut: Muassasah al-Risalah.

Reeder, Sharon J., dkk, 2011. Keperawatan maternitas; Kesehatan Wanita, Bayi dan Keluarga, Jakarta: Penerbit Buku Kedokteran EGC.

Rijal Hamid, Syamsu. 1999. Buku Pintar Agama Islam, cet. ke-5, Jakarta: Penebar Salam.
Sabiq, Sayyid. 1987. Fiqh al-Sunnâh, juz 2, Kairo: Dar al-Fikr.

Serapung, Elga, dkk. 1999. Agama dan Kesehatan Reproduksi, Jakarta: Pustaka Sinar Harapan,

al-Tirmidzi, Abu Isa, Sunan alTirmidzi, Riyad: Maktabah alMa'arif,tt, cet.1 Software Jami' alHadits

Verawaty, Sri Noor dan Liswidyawati Rahayu. 2012. Merawat dan Menjaga Kesehatan Seksual Wanita, Bandung: PT. Grafindo Media Pratama.

al-Zuhaili, Wahbah. 1989. al-Figh alIslam wa Adillatuhu, Damaskus: Daar al-Fikr.

al-Qardhawi, Yusuf. 2009. Fatawa Mu'ashirah, cet. 1, Kairo: Dar alQalam. 